\title{
Left ventricular mass by cardiac magnetic resonance imaging and adverse cardiovascular outcomes in patients treated with anthracycline- based chemotherapy
}

Tomas G Neilan ${ }^{1,2^{*}}$, Diego Pena-Herrera², Otavio R Coelho-Filho² ${ }^{2}$, Michael Jerosch-Herold ${ }^{3}$, Javid Moslehi ${ }^{2}$, Raymond Kwong ${ }^{2}$

From 15th Annual SCMR Scientific Sessions

Orlando, FL, USA. 2-5 February 2012

\section{Summary}

LV mass by CMR is a powerful predictor of adverse cardiovascular outcomes in patients treated with anthracyclines.

\section{Background}

Late gadolinium enhancement (LGE) is a predictor of adverse outcomes in patients. However, limited data exist on the role of LGE, the characteristic CMR findings, and the prognostic variables in patients who develop a cardiomyopathy after treatment with anthracyclines.

\section{Methods}

LGE-CMR imaging was performed in patients with stage $B$ and $C$ heart failure after anthracycline-based chemotherapy. We assessed the association between CMR, EKG, echocardiographic, serum, and clinical variables with adverse outcomes (cardiovascular death and admission for heart failure).

\section{Results}

We performed a clinically-indicated CMR study on 50 patients (52\% male, mean age of $49 \pm 16$ years, anthracycline dose of $286 \pm 89 \mathrm{mg} / \mathrm{m} 2$, and ejection fraction of 38 $\pm 9 \%)$ with AC-mediated cardiomyopathy. Patients presented a median of 45 months after chemotherapy and were followed for a median period of 28 months. LGE was an uncommon finding ( 3 patients, $6 \%$ ). There was a

${ }^{1}$ Medicine, Massachusetts General Hospital, Boston, MA, USA

Full list of author information is available at the end of the article strong inverse association between anthracycline dose and indexed left ventricular mass by CMR $(r=-.75, p<$ 0.001 , Figure 1). In univariate analysis, indexed LV-mass by CMR demonstrated the strongest unadjusted association with adverse events (hazard ratio: 0.75, chi-squared 26.2, $\mathrm{p}<0.001$ ). In a multivariable model, indexed LVmass demonstrated the strongest association with the primary outcome (Figure 2).

\section{Conclusions}

Residual LV-mass measured by CMR is a powerful predictor of subsequent adverse cardiovascular events in patients with anthracycline-induced cardiotoxicity.

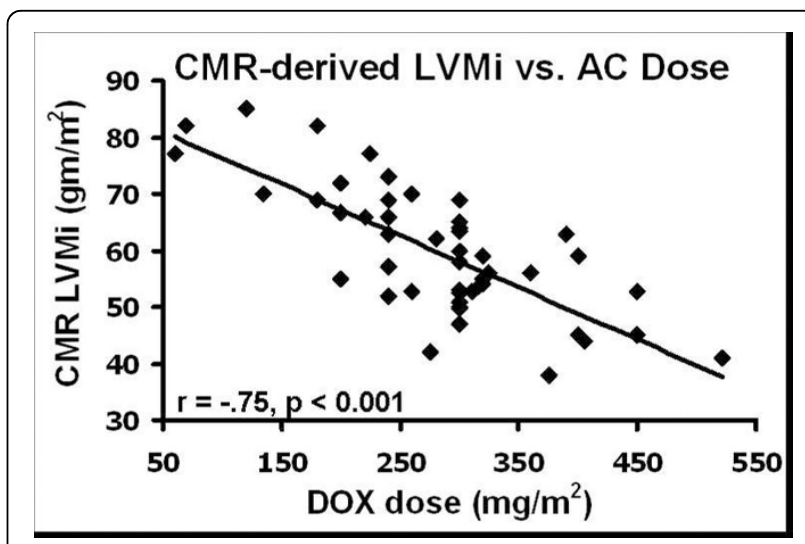

Figure 1

(C) 2012 Neilan et al; licensee BioMed Central Ltd. This is an open access article distributed under the terms of the Creative Commons 


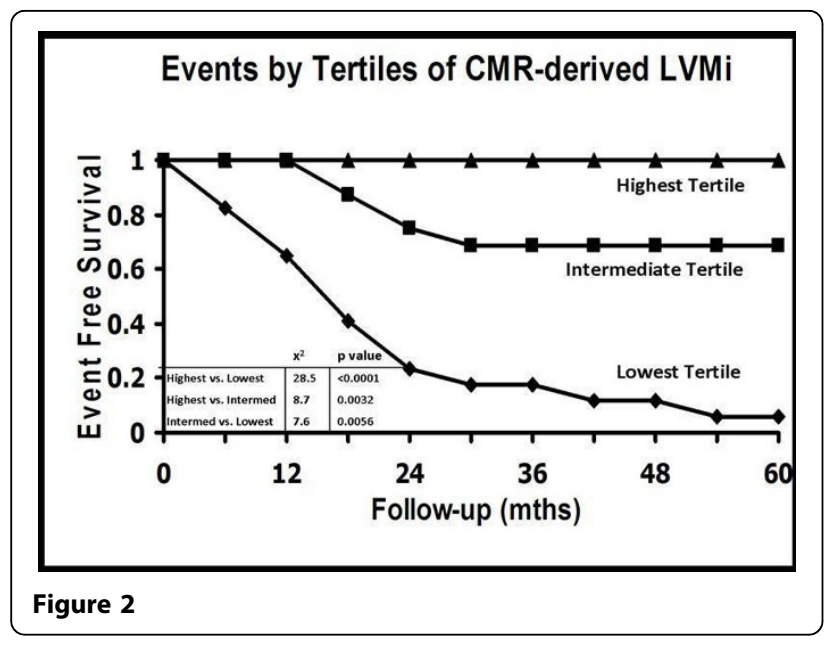

\section{Funding}

Dr. Neilan is supported by an NIH T32 Training Grant (T32HL09430101A1).

\section{Author details}

${ }^{1}$ Medicine, Massachusetts General Hospital, Boston, MA, USA. ${ }^{2}$ Medicine, Brigham and Women's Hospital, Boston, MA, USA. ${ }^{3}$ Radiology, Brigham and Women's Hospital, Boston, MA, USA.

Published: 1 February 2012

doi:10.1186/1532-429X-14-S1-030

Cite this article as: Neilan et al:: Left ventricular mass by cardiac magnetic resonance imaging and adverse cardiovascular outcomes in patients treated with anthracycline-based chemotherapy. Journal of Cardiovascular Magnetic Resonance 2012 14(Suppl 1):O30.

Submit your next manuscript to BioMed Central and take full advantage of:

- Convenient online submission

- Thorough peer review

- No space constraints or color figure charges

- Immediate publication on acceptance

- Inclusion in PubMed, CAS, Scopus and Google Scholar

- Research which is freely available for redistribution

Submit your manuscript at www.biomedcentral.com/submit 